\title{
Changes in Breathing Variables During a 30-Minute Spontaneous Breathing Trial
}

\author{
Juan B Figueroa-Casas MD, Sean M Connery MSc, and Ricardo Montoya RRT
}

\begin{abstract}
BACKGROUND: Spontaneous breathing trials (SBTs) are increasingly performed. Significant changes in monitored breathing variables and the timing of those changes during the trial have important implications for its outcome determination and supervision. We aimed to study the magnitude and timing of change in breathing variables during the course of a 30-min SBT. METHODS: Breathing variables were continuously measured and averaged by minute during the SBT in 32 subjects with trial success and 8 subjects with trial failure from a general ICU population. Percentage changes in breathing variables during the trial and proportions of subjects showing a $\geq 20 \%$ change at different time points relative to the second minute of the trial were calculated. RESULTS: The commonly monitored breathing variables (frequency, tidal volume, their ratio, and minute ventilation) showed median coefficients of variation of $<15 \%$ throughout the trial and a median change of less than $\pm 20 \%$ by the end of the trial. Changes in a detrimental direction of $\geq 20 \%$ at the end of the trial but not already present at $10 \mathrm{~min}$ were noted in $\leq 5 \%$ of all subjects. CONCLUSIONS: During the course of a 30-min SBT, breathing variables remain relatively constant, and potentially significant changes in these variables after $10 \mathrm{~min}$ into the trial are uncommon. These findings should be considered when addressing aspects of duration and supervision of SBTs in weaning protocols. Key words: ventilator weaning; mechanical ventilator; breathing mechanics; resource allocation. [Respir Care 2015;60(2):155-161. ( ) 2015 Daedalus Enterprises]
\end{abstract}

\section{Introduction}

A spontaneous breathing trial (SBT) is the recommended final test in the process of weaning from mechanical ventilation $^{1}$ and a routine component of increasingly used systematic weaning protocols. ${ }^{2,3}$ During the trial, breathing

Dr Figueroa-Casas is affiliated with the Division of Pulmonary and Critical Care Medicine, and Mr Connery is affiliated with the Department of Medicine, Paul L Foster School of Medicine, Texas Tech University Health Sciences Center, El Paso, Texas. Mr Montoya is affiliated with the Department of Respiratory Care, University Medical Center of El Paso, El Paso, Texas.

This work was supported in part by a Texas Tech University Health Sciences Center seed grant. The authors have disclosed no conflicts of interest.

Correspondence: Juan B Figueroa-Casas MD, Division of Pulmonary and Critical Care Medicine, Paul L Foster School of Medicine, Texas Tech University Health Sciences Center, 4800 Alberta Ave, Suite 136, El Paso, TX 79905. E-mail: juan.figueroa@ttuhsc.edu.

DOI: $10.4187 /$ respcare. 03385 variables are monitored and used to determine its outcome. The commonly used trial duration of 30 min or more implies that changes in monitored variables can develop during this period. The magnitude and timing of these changes can have important implications for result determination and supervision of the trial.

See the Related Editorial on Page 306

Significant changes in breathing variables during the trial would potentially yield different SBT outcome results according to the moment selected for the measurements or the total duration of the trial. Significant changes would also suggest that variables derived from serial measurements over the course of the trial be evaluated as possibly superior SBT outcome determinants..$^{4,5}$ In addition, significant changes would demand very close monitoring of the trial, as an excessive ventilatory load not promptly recognized during the SBT could conceivably lead to prolonged respiratory muscle fatigue. ${ }^{6}$ However, an uninterrupted 30 min period of supervision by respiratory therapists can be 


\section{Changes in Breathing Variables During SBTs}

difficult to achieve in busy ICUs with a high scheduled and unscheduled work load. ${ }^{7}$

The demand for performing SBTs is likely to increase as bundle-type care in weaning is increasingly implemented. ${ }^{8}$ Therefore, further knowledge of the potential change in variables over the trial duration would assist in planning its safe and efficient performance. We aimed to study the magnitude and timing of change in breathing variables during the course of a 30-min SBT.

\section{Methods}

In this study, we continuously measured breathing variables during SBTs performed for clinical purpose as part of an institutional weaning protocol. This study was performed in the 30-bed ICU of the University Medical Center of El Paso (El Paso, Texas), which admits adult medical, surgical, and trauma patients. The ICU has a singleventilator weaning protocol that is applied daily to all ventilated patients and is described below. The study was approved by the local institutional review board, and informed consent was obtained from subjects or their next of kin.

\section{Subjects}

Subjects eligible for inclusion were 18 y or older, were intubated on mechanical ventilation for at least $48 \mathrm{~h}$, and had an SBT ordered by the treating ICU team. Subjects with tracheostomy or needing trial discontinuation within a few minutes of starting were excluded. Clinical data collected included: age, primary diagnosis leading to mechanical ventilation, duration of ventilation, Acute Physiology and Chronic Health Evaluation II score and the $\mathrm{P}_{\mathrm{aO}_{2}} / \mathrm{F}_{\mathrm{IO}_{2}}$ on the morning of the studied SBT, the breathing frequency/tidal volume $\left(\mathrm{f} / \mathrm{V}_{\mathrm{T}}\right)$ ratio measured before deciding to perform the SBT, and the outcome of the trial (success or failure). Heart rate, systolic blood pressure, and $\mathrm{S}_{\mathrm{pO}_{2}}$ before the start and at the end of the SBT were also collected.

\section{Weaning Protocol Description}

All subjects undergoing mechanical ventilation were screened daily by a respiratory therapist for the following criteria: $\mathrm{F}_{\mathrm{IO}_{2}} \leq 50 \%$, PEEP $\leq 5 \mathrm{~cm} \mathrm{H} \mathrm{H}_{2} \mathrm{O}$, minute ventilation $<15 \mathrm{~L} / \mathrm{min}, \mathrm{P}_{\mathrm{aO}_{2}} / \mathrm{F}_{\mathrm{IO}_{2}} \geq 150 \mathrm{~mm} \mathrm{Hg}, \mathrm{f} / \mathrm{V}_{\mathrm{T}} \leq 105$ breaths $/ \mathrm{min} / \mathrm{L}$ (while on CPAP of $5 \mathrm{~cm} \mathrm{H}_{2} \mathrm{O}$ without pressure support for $1 \mathrm{~min}$ ), presence of cough and gag reflex, absence of sedative or vasopressor infusions, and Glasgow coma scale $\geq 10$. Upon meeting all screening criteria, ICU physicians made a decision regarding ordering an SBT, but this could also be ordered even if not all

\section{QUICK LOOK}

\section{Current knowledge}

Spontaneous breathing trials (SBTs) are recognized as the standard of care for evaluating patient readiness for ventilator discontinuation. A trial of $30 \mathrm{~min}$ is commonly employed with monitoring of patient comfort and physiologic variables. Measurements at the end of the trial are typically utilized to evaluated success or failure.

\section{What this paper contributes to our knowledge}

In a small group of subjects from a general ICU, over the course of a 30-min SBT, measured variables remained relatively constant. Potentially significant changes in measured variables after $10 \mathrm{~min}$ of the trial were uncommon.

screening criteria were met when physicians considered it appropriate. All SBTs were performed on CPAP of $5 \mathrm{~cm} \mathrm{H}_{2} \mathrm{O}$ without pressure support and were supervised by respiratory therapists for a maximum duration of $30 \mathrm{~min}$. Trial failure was defined as meeting any one of the following criteria: breathing frequency $>35$ breaths/min, $\mathrm{S}_{\mathrm{pO}_{2}}<90 \%$, change in heart rate $>20 \%$, increase in systolic blood pressure $>25 \%$, presence of agitation, diapho-

Table 1. Characteristics of Subjects on Day of Spontaneous Breathing Trial

\begin{tabular}{|c|c|c|c|}
\hline Characteristic & $\begin{array}{c}\text { All } \\
(N=40)\end{array}$ & $\begin{array}{l}\text { Success } \\
(n=32)\end{array}$ & $\begin{array}{l}\text { Failure } \\
(n=8)\end{array}$ \\
\hline Age (mean $\pm S D), y$ & $61.3 \pm 13.7$ & $60.9 \pm 14.9$ & $62.6 \pm 7.8$ \\
\hline \multicolumn{4}{|l|}{ Diagnosis, $\%$} \\
\hline ARDS & 32.5 & 31.3 & 37.5 \\
\hline $\begin{array}{l}\text { Congestive heart failure } \\
\text { exacerbation }\end{array}$ & 20 & 21.9 & 12.5 \\
\hline COPD exacerbation & 17.5 & 15.6 & 25 \\
\hline Multiple trauma & 10 & 12.5 & 0 \\
\hline Postoperative & 7.5 & 9.4 & 0 \\
\hline Other & 12.5 & 9.4 & 25 \\
\hline $\begin{array}{l}\text { Duration of ventilation, } \\
\text { median (IQR), d }\end{array}$ & $5(3-8)$ & $5(3-8)$ & $6(4-8)$ \\
\hline $\begin{array}{r}\text { APACHE II score } \\
(\text { mean } \pm \mathrm{SD})\end{array}$ & $15.6 \pm 4.8$ & $15.7 \pm 5$ & $15.5 \pm 4.6$ \\
\hline $\begin{array}{c}\mathrm{P}_{\mathrm{aO}_{2}} / \mathrm{F}_{\mathrm{IO}_{2}}, \text { median }(\mathrm{IQR}), \\
\mathrm{mm} \mathrm{Hg}\end{array}$ & $190(172-240)$ & $190(173-240)$ & $179(153-229)$ \\
\hline $\begin{array}{c}\mathrm{f} / \mathrm{V}_{\mathrm{T}}(\text { mean } \pm \mathrm{SD}) \\
\text { breaths } / \mathrm{min} / \mathrm{L}\end{array}$ & $79.4 \pm 29.7$ & $75.9 \pm 28.1$ & $93.1 \pm 34$ \\
\hline \multicolumn{4}{|c|}{$\begin{array}{l}\text { IQR }=\text { interquartile range } \\
\text { APACHE II }=\text { Acute Physiology and Chronic Health Evaluation II } \\
\text { f } / \mathrm{V}_{\mathrm{T}}=\text { breathing frequency/tidal volume ratio prior to the spontaneous breathing trial }\end{array}$} \\
\hline
\end{tabular}



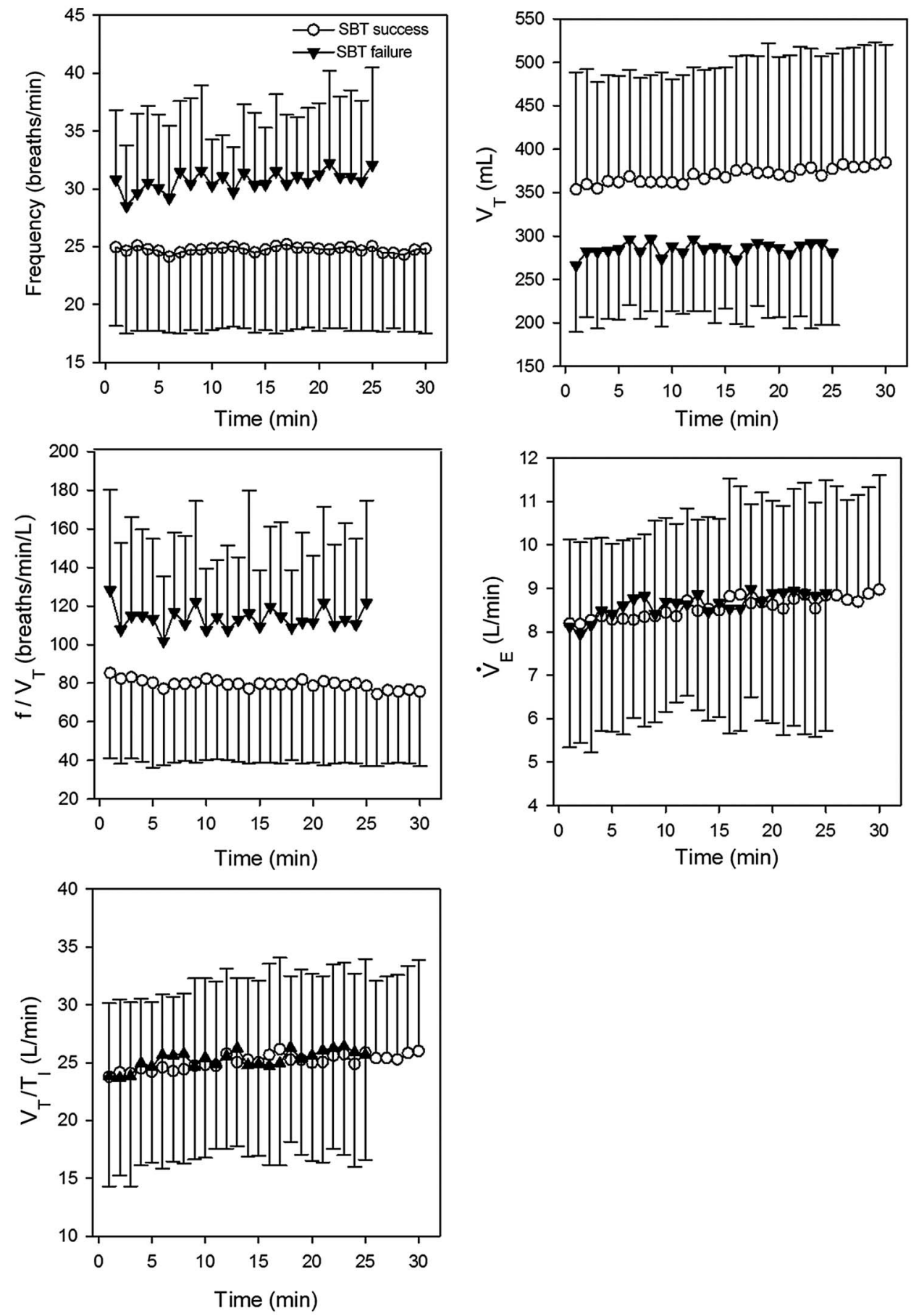

Fig. 1. Minute-by-minute means of breathing variables during the spontaneous breathing trial for the groups of subjects with trial success $(n=32)$ and failure $(n=8)$. Error bars indicate $1 \mathrm{SD}$. $\mathrm{V}_{\mathrm{T}}=$ tidal volume; $\mathrm{f}=$ breathing frequency; $\dot{\mathrm{V}}_{\mathrm{E}}=$ minute ventilation; $\mathrm{V}_{\mathrm{T}} / \mathrm{T}_{1}=$ mean inspiratory flow.

resis, or use of accessory muscles for respiration. The decisions to perform and to discontinue an SBT and the determination of its outcome were up to the treating physicians and respiratory therapists and independent of the observations of the investigators.

\section{Measurement of Breathing Variables During the SBT}

Subjects were endotracheally suctioned and placed in a semirecumbent position before starting the SBT. An RSS 100HR Research Pneumotach system (Hans Rudolph, 

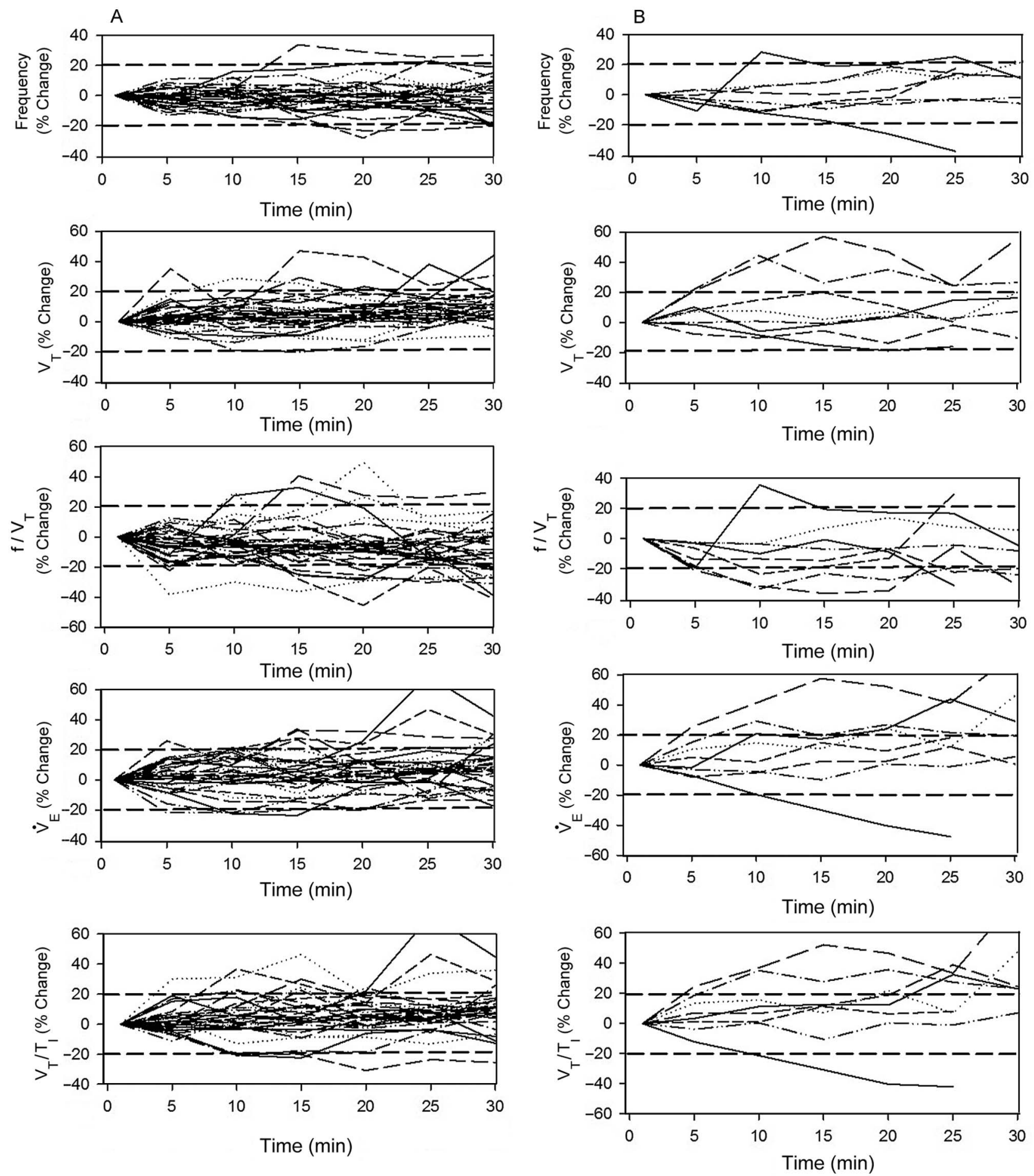

Fig. 2. Percentage changes relative to minute 1 in breathing variables at 5 -min intervals during the spontaneous breathing trial for individual subjects with trial success $(A)$ and failure $(B) . V_{T}=$ tidal volume; $f=$ breathing frequency; $\dot{V}_{E}=$ minute ventilation; $V_{T} / T_{1}=$ mean inspiratory flow. The dashed horizontal lines mark $\pm 20 \%$ relative to minute 1 .

Shawnee, Kansas) was used. The pneumotachograph, placed between the endotracheal tube and the Y-piece of the ventilator tubing, measured airway flow (by differential pressure) and pressure at a sample rate of $50 \mathrm{~Hz}$. De- 


\section{Changes in Breathing Variables During SBTs}

rived breathing variables were calculated by the system and stored in a personal computer for posterior calculations and analysis. One of the investigators was present during the entire duration of the measurements and noted episodes of coughing, gagging, and movement that affected recordings but did not represent a change in breathing pattern for posterior discard of these segments of data before analysis. Breath-by-breath values of $\mathrm{V}_{\mathrm{T}}$, breathing frequency, $\mathrm{f} / \mathrm{V}_{\mathrm{T}}$, minute ventilation, and mean inspiratory flow $\left(\mathrm{V}_{\mathrm{T}} / \mathrm{T}_{\mathrm{I}}\right)$ were averaged at 1-min intervals after the start of the SBT. Data recorded in the first minute of the SBT (minute 0) was discarded from the analysis, as it was considered to reflect a transition from positive-pressure ventilatory support to spontaneous ventilation and therefore not a good reference for comparison with subsequent minutes. The second minute of the trial was then termed minute 1 .

\section{Data Analysis}

Data were summarized using proportion, mean $\pm \mathrm{SD}$, or median and interquartile range according to the type of variable and distribution of the data. Changes in breathing variables over the course of the SBT were analyzed with the following measures. For each subject, the coefficient of variation (\%) of a variable was calculated as $\mathrm{SD} /$ mean (of the values of all minutes of the SBT) $\times 100$. For each subject, the change in a variable at a given minute of the SBT was calculated as the percentage change at that minute relative to minute 1 of the SBT. Proportions of subjects showing $\geq 20 \%$ change (relative to minute 1) in a variable at a given minute of the trial were calculated. Precisions of these estimates were calculated with $95 \% \mathrm{CI}^{9}$ for the whole group, but not for proportions equal to zero or subgroups given sample size.

\section{Results}

Forty SBTs performed in 40 different subjects were included. Thirty-two subjects passed the trial and were extubated on the same day. Seven of these were re-intubated within $48 \mathrm{~h}$. Eight subjects failed the trial by meeting at least one failure criterion. For 2 failed SBT subjects, the trial was interrupted between minutes 25 and 30 . The other 6 subjects who failed the SBT completed $30 \mathrm{~min}$ of the trial. No subject showed a change in heart rate or blood pressure meeting failure thresholds during the trial. Two subjects showed oxygen desaturation below $90 \%$.

Subjects' characteristics on the day of the evaluated SBT are provided in Table 1. Descriptive minute-by-minute breathing variable summary data for subjects passing and failing the SBT are shown in Figure 1. For the failure group, the data were summarized up to minute 25 , when data for all subjects were available.
Table 2. Measures of Change in Breathing Variables During a 30-min SBT

\begin{tabular}{|c|c|c|}
\hline & $\begin{array}{l}\text { Coefficient of } \\
\text { Variation }(\%)\end{array}$ & $\begin{array}{l}\text { Change at Last } \\
\text { Minute Relative } \\
\text { to Minute } 1(\%)\end{array}$ \\
\hline \multicolumn{3}{|l|}{ Breathing frequency } \\
\hline All subjects* & $5.6(3.7-7.7)$ & $1.7(-6.4$ to 9.3$)$ \\
\hline Successful SBT subjects $\dagger$ & $5.2(3.7-7.6)$ & $1.5(-8.5$ to 8.1$)$ \\
\hline Failed SBT subjects $\ddagger$ & $7.0(5.4-10.6)$ & $11.4(-2.7$ to 13.4$)$ \\
\hline \multicolumn{3}{|l|}{$\mathrm{V}_{\mathrm{T}}$} \\
\hline All subjects & $5.0(4.1-7.9)$ & $8.6(2.4-16.9)$ \\
\hline Successful SBT subjects & $4.7(3.9-6.5)$ & $8.6(3.5-16.1)$ \\
\hline Failed SBT subjects & $7.3(5.7-9.4)$ & $11.8(-2.1$ to 21.8$)$ \\
\hline \multicolumn{3}{|l|}{$\mathrm{f} / \mathrm{V}_{\mathrm{T}}$} \\
\hline All subjects & $8.6(6.9-12.3)$ & $-10.7(-21.3$ to 1.1$)$ \\
\hline Successful SBT subjects & $8.0(6.9-10.2)$ & $-10.7(-20.4$ to 1.1$)$ \\
\hline Failed SBT subjects & $13.3(9.5-15.7)$ & $-13.9(-25.8$ to 1.8$)$ \\
\hline \multicolumn{3}{|c|}{ en } \\
\hline All subjects & $7.7(5.3-10.5)$ & $9.1(1.7-19.8)$ \\
\hline Successful SBT subjects & $7.2(4.2-9.5)$ & $7.7(0.6-15.4)$ \\
\hline Failed SBT subjects & $9.5(7.3-11.4)$ & $18.8(4.2-33.3)$ \\
\hline \multicolumn{3}{|l|}{$\mathrm{V}_{\mathrm{T}} / \mathrm{T}_{\mathrm{I}}$} \\
\hline All subjects & $7.7(4.7-9.8)$ & $9.7(5.3-17.8)$ \\
\hline Successful SBT subjects & $6.2(3.6-9.4)$ & $9.3(4.9-15.6)$ \\
\hline Failed SBT subjects & $8.9(7.6-11.2)$ & $23.1(7.6-30.3)$ \\
\hline $\begin{array}{l}\text { Data are expressed as the median (inter } \\
* n=40 \\
\dagger n=32 \\
\ddagger n=8 \\
\text { SBT }=\text { spontaneous breathing trial } \\
\mathrm{V}_{\mathrm{T}}=\text { tidal volume } \\
\mathrm{V}_{\mathrm{E}}=\text { minute ventilation } \\
\mathrm{V}_{\mathrm{T}} / \mathrm{T}_{\mathrm{I}}=\text { mean inspiratory flow }\end{array}$ & uartile range). & \\
\hline
\end{tabular}

The percentage changes relative to minute 1 in breathing variables at 5-min intervals for individual subjects are shown in Figure 2. Summary measures of change in breathing variables during the trial are shown in Table 2. Proportions of subjects with selected magnitudes and timing of change for each variable are shown in Table 3.

\section{Discussion}

In this study, we measured breathing variables throughout the SBT in subjects that passed or failed the trial and obtained the following main findings: median coefficients of variation for breathing variables were below $15 \%$, and their median changes from the start to the end of the trial were $<20 \%$. In addition, for the variables most commonly monitored during the SBT, we found that $\leq 5 \%$ of all subjects showed a detrimental change of $\geq 20 \%$ (increase in breathing frequency, decrease in $\mathrm{V}_{\mathrm{T}}$, increase in $\mathrm{f} / \mathrm{V}_{\mathrm{T}}$ ) from the start to the last minute of the trial that was not already present at $10 \mathrm{~min}$ into it. We interpret these findings as indicating that during the course of a 30-min SBT, breathing variables remain relatively constant. 
Table 3. Proportions of Subjects With Selected Percentage Change Relative to Minute 1

\begin{tabular}{|c|c|c|c|}
\hline & $\begin{array}{l}\text { Change } \pm 20 \% \text { or More } \\
\text { at Last Minute }\end{array}$ & $\begin{array}{c}\text { Decrease } \geq 20 \% \text { at Last Minute, } \\
\text { but }<20 \% \text { at Minute } 10\end{array}$ & $\begin{array}{c}\text { Increase } \geq 20 \% \text { at Last Minute, } \\
\text { but }<20 \% \text { at Minute } 10\end{array}$ \\
\hline \multicolumn{4}{|l|}{ Breathing frequency } \\
\hline All subjects* & $15.0(10-26)$ & $10.0(1-19)$ & $5.0(0-12)$ \\
\hline Successful SBT subjects $\dagger$ & 12.5 & 9.4 & 3.1 \\
\hline Failed SBT subjects $\ddagger$ & 25.0 & 12.5 & 12.5 \\
\hline \multicolumn{4}{|l|}{$\mathrm{V}_{\mathrm{T}}$} \\
\hline All subjects & $17.5(6-29)$ & 0 & $12.5(2-22)$ \\
\hline Successful SBT subjects & 12.5 & 0 & 12.5 \\
\hline Failed SBT subjects & 37.5 & 0 & 12.5 \\
\hline \multicolumn{4}{|l|}{$\mathrm{f} / \mathrm{V}_{\mathrm{T}}$} \\
\hline All subjects & $40.0(25-55)$ & $27.5(14-41)$ & $5.0(0-12)$ \\
\hline Successful SBT subjects & 34.4 & 28.1 & 3.1 \\
\hline Failed SBT subjects & 62.5 & 25.0 & 12.5 \\
\hline \multicolumn{4}{|l|}{$\dot{\mathrm{V}}_{\mathrm{E}}$} \\
\hline All subjects & $30.0(16-44)$ & 0 & $15.0(4-26)$ \\
\hline Successful SBT subjects & 21.9 & 0 & 15.6 \\
\hline Failed SBT subjects & 62.5 & 0 & 12.5 \\
\hline \multicolumn{4}{|l|}{$\mathrm{V}_{\mathrm{T}} / \mathrm{T}_{\mathrm{I}}$} \\
\hline All subjects & $30.0(16-44)$ & 0 & $12.5(2-23)$ \\
\hline Successful SBT subjects & 18.7 & 0 & 6.3 \\
\hline Failed SBT subjects & 75.0 & 0 & 37.5 \\
\hline $\begin{array}{l}\text { Proportions are expressed as percent }( \\
* n=40 \\
\dagger n=32 \\
\ddagger n=8 \\
\mathrm{~V}_{\mathrm{T}}=\text { tidal volume } \\
\dot{\mathrm{V}}_{\mathrm{E}}=\text { minute ventilation } \\
\mathrm{V}_{\mathrm{T}} / \mathrm{T}_{\mathrm{I}}=\text { mean inspiratory flow }\end{array}$ & & & \\
\hline
\end{tabular}

We analyzed change over time as a percentage rather than absolute change and estimated the proportion of subjects who developed more than a threshold change for each variable at different time points. These analyses were intended to enhance the clinical interpretation of the results and focused on all subjects undergoing an SBT. Data for successful and failed SBT subjects were also reported to further inform about these subgroups, but the study was not designed to test for possible differences between them.

The 20\% change threshold used for analysis was selected as a conservative level of significant change based on the following reasons: this level is the lowest percentage change used as indicative of a meaningful change in any variable monitored during an SBT in large weaning studies $^{2,10}$; it is just below the lowest mean coefficient of variation for breathing variables reported in normal subjects ${ }^{11}$; and it is the best threshold described to predict successful extubation when change in $\mathrm{f} / \mathrm{V}_{\mathrm{T}}$ was analyzed periodically during a 2 -h SBT. ${ }^{4}$ The $10-$ min time point for comparison with the last minute of the trial was selected as the end of a period of reasonable uninterrupted supervision and a potentially meaningful decrease in SBT duration.

The following limitations of this study need to be considered. First, the subject selection of this study included general ICU patients undergoing SBTs as a routine part of a systematic weaning protocol driven and supervised by respiratory therapists, which may not be applicable to a different setting. Second, this study did not cover changes that may develop during an SBT when it is prolonged for up to $2 \mathrm{~h}$, a duration also frequently used. However, 30min versus 120-min SBTs have been shown to yield no differences in trial or extubation success rates, ${ }^{10}$ suggesting that significant changes in breathing variables are unlikely beyond $30 \mathrm{~min}$. Third, this study did not measure or record continuous changes in the non-breathing variables monitored during the SBT, such as hemodynamic, oxygenation, or respiratory distress subjective variables. However, no subject in this study showed a change in hemodynamic variables meeting failure thresholds, and only 2 subjects developed hypoxemia between the start and end of the trial. Subjective variables that evaluate respiratory distress are more difficult to reliably detect and quantify and were also not serially measured in this study. As a conceivable but unproven surrogate of signs of respiratory distress, this study measured and reported $\mathrm{V}_{\mathrm{T}} / \mathrm{T}_{\mathrm{I}}$, an index of neuromuscular inspiratory drive. ${ }^{12}$ Although $\mathrm{V}_{\mathrm{T}} / \mathrm{T}_{\mathrm{I}}$ was previously noted to increase during the SBT in failed trial subjects only, ${ }^{13}$ more recently, it was reported to be similar 


\section{Changes in Breathing Variables During SBTs}

between and to increase during the trial in both successful and failed trial subjects. ${ }^{14}$ Our finding of an overlapping mean course of this variable for successful and failed SBT subjects further questions this variable as indicative of increased respiratory effort or distress during the trial. Finally, it should be noted that, as allowed by the weaning protocol and ordered by clinicians, some subjects had an $\mathrm{f} / \mathrm{V}_{\mathrm{T}}$ of $>105$ breaths/min/L before or right after the start of the SBT, which could increase their probability of weaning failure. All subjects undergoing SBT regardless of their screening $\mathrm{f} / \mathrm{V}_{\mathrm{T}}$ were included in order for the analysis to be comprehensive and reflect clinical practice.

Few prior studies have carefully measured change in breathing variables during the SBT. Jubran and Tobin ${ }^{14}$ reported no significant absolute changes in $\mathrm{V}_{\mathrm{T}}$, breathing frequency, and $f / V_{T}$ when these variables were periodically measured at quartiles of the SBT duration in successful or failed trial subjects with COPD. In a later study, Jubran et al ${ }^{15}$ also found that $\mathrm{f} / \mathrm{V}_{\mathrm{T}}$ and esophageal pressure swings reach $\pm 10 \%$ of their final values for the SBT within a median (interquartile range) of $2(1-2) \mathrm{min}$ and 8 (4-15) min, respectively. These studies are in line with the current findings and together suggest that it is highly unlikely that clinically relevant changes develop after $15 \mathrm{~min}$ into the trial. An initial brief period of close clinical supervision of the SBT with subsequent periodic evaluations seems therefore appropriate, and a short-duration SBT for subjects identified at low risk for trial failure ${ }^{16}$ can be reasonably tested in future studies.

\section{Conclusions}

During the course of a 30-min SBT, breathing variables remain relatively constant, and potentially significant changes in these variables after $10 \mathrm{~min}$ of the trial are uncommon. These findings should be considered when addressing aspects of duration and supervision of SBTs in systematic weaning protocols.

\section{REFERENCES}

1. MacIntyre NR. Evidence-based guidelines for weaning and discontinuing ventilatory support: a collective task force facilitated by the American College of Chest Physicians, the American Association for
Respiratory Care, and the American College of Critical Care Medicine. Chest 2001;120(6):375S-395S.

2. Ely EW, Baker AM, Dunagan DP, Burke HL, Smith AC, Kelly PT, et al. Effect on the duration of mechanical ventilation of identifying patients capable of breathing spontaneously. N Engl J Med 1996; 335(25):1864-1869.

3. Girard TD, Kress JP, Fuchs BD, Thomason JW, Schweickert WD, Pun BT, et al. Efficacy and safety of a paired sedation and ventilator weaning protocol for mechanically ventilated patients in intensive care (Awakening and Breathing Controlled trial): a randomised controlled trial. Lancet 2008;371(9607):126-134.

4. Segal LN, Oei E, Oppenheimer BW, Goldring RM, Bustami RT, Ruggiero S, et al. Evolution of pattern of breathing during a spontaneous breathing trial predicts successful extubation. Intensive Care Med 2010;36(3):487-495.

5. Teixeira C, Zimermann Teixeira PJ, Hohër JA, de Leon PP, Brodt $\mathrm{SF}$, da Siva Moreira J. Serial measurements of $\mathrm{f} / \mathrm{V}_{\mathrm{T}}$ can predict extubation failure in patients with $\mathrm{f} / \mathrm{V}_{\mathrm{T}} \leq 105$ ? J Crit Care 2008; 23(4):572-576

6. Laghi F, D'Alfonso N, Tobin MJ. Pattern of recovery from diaphragmatic fatigue over 24 hours. J Appl Physiol 1995;79(2):539-546.

7. Ford RM. Staffing the respiratory care department: new considerations. Respir Care 2011;56(11):1864-1865.

8. Vasilevskis EE, Ely EW, Speroff T, Pun BT, Boehm L, Dittus RS. Reducing iatrogenic risks: ICU-acquired delirium and weaknesscrossing the quality chasm. Chest 2010;138(5):1224-1233.

9. Gardner MJ, Altman DG. Confidence intervals rather than $P$ values: estimation rather than hypothesis testing. BMJ 1986;292(6522):746750.

10. Esteban A, Alía I, Tobin MJ, Gil A, Gordo F, Vallverdú I, et al Effect of spontaneous breathing trial duration on outcome of attempts to discontinue mechanical ventilation. Am J Respir Crit Care Med 1999;159(2):512-518.

11. Tobin MJ, Mador MJ, Guenther SM, Lodato RF, Sackner MA. Variability of resting respiratory drive and timing in healthy subjects. J Appl Physiol 1988;65(1):309-317.

12. Milic-Emili J, Aubier M. Some recent advances in the study of the control of breathing in patients with chronic obstructive lung disease. Anesth Analg 1980;59(11):865-873.

13. Tobin MJ, Perez W, Guenther SM, Semmes BJ, Mador MJ, Allen SJ, et al. The pattern of breathing during successful and unsuccessful trials of weaning from mechanical ventilation. Am Rev Respir Dis 1986;134(6):1111-1118

14. Jubran A, Tobin M. Pathophysiologic basis of acute respiratory distress in patients who fail a trial of weaning from mechanical ventilation. Am J Respir Crit Care Med 1997;155(3):906-915.

15. Jubran A, Grant BJ, Laghi F, Parthasarathy S, Tobin MJ. Weaning prediction: esophageal pressure monitoring complements readiness testing. Am J Respir Crit Care Med 2005;171(11):1252-1259.

16. Yang KL, Tobin MJ. A prospective study of indexes predicting the outcome of trials of weaning from mechanical ventilation. N Engl J Med 1991;324(21):1445-1450.

This article is approved for Continuing Respiratory Care Education credit. For information and to obtain your CRCE

(free to AARC members) visit www.rcjournal.com

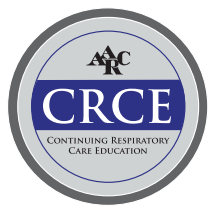

